\title{
MODELO CRIATIVO E AVALIAÇÃO NO DESIGN
}

Marcelo José da Mota

Faculdade de Engenharia de Presidente Prudente - FEPP. Curso Superior de Tecnologia em Design de Interiores UNOESTE. E-mail: marcelomota@unoeste.br

\section{RESUMO}

Este artigo pretende fomentar o método no Design e na avaliação do ensino/aprendizagem. em disciplinas práticas que tenha como resultado uma produção inovadora e criativa regida por aspectos cognitivos perceptíveis e possíveis de serem avaliados. Alicerça-se em ferramentas pedagógicas e nas reflexões construtivas que visam a avaliação do ensino/aprendizagem não somente nos cursos de Design, mas também de Arquitetura, de Publicidade, entre outros, com disciplinas que necessitem de metodologia e de criatividade em projetos experimentais. A proposta é propor um parâmetro metodológico que incentiva, compreende, estabelece relações culturais, plásticas e afetivas para o desenvolvimento do projeto. Neste sentido, auxiliará no planejamento de disciplinas práticas na elaboração, na execução e principalmente na avaliação do processo educativo.

Palavras-chave: Design, Método, Criatividade, Avaliação e Educação

\section{INTRODUÇÃO}

Os escritos a seguir orientam para um processo sócio-interacionista, ou seja, os atores envolvidos na troca de experiências e de oportunidades no ensino/aprendizado do design. As ferramentas metodológicas e de avaliação aqui descritas, objetiva a otimização e a hibridez do trabalho educativo no planejamento, na transmissão do conhecimento e na execução de ações. 0 objetivo deste projeto é fomentar o método no Design e na avaliação do ensino/aprendizagem com uma produção inovadora e criativa regida por aspectos cognitivos perceptíveis e possíveis de serem avaliados.

A metodologia utilizou-se de recursos qualitativos através de uma revisão bibliográfica sobre método criativo para o ensino do Design, dos autores Fuentes (2006), Gomes (2004), Westin e Coelho (2011), bem como reflexões sobre os sistemas de avaliação de Oliveira (2004). Os autores escrevem sobre os caminhos da Educação para o desenvolvimento de um projeto de Design através de um modelo dividido em fases, etapas e processo avaliativo. A proposta sugerida aumenta o controle do projeto, ativa a memória visual e as referências culturais, bem como possibilita novas alternativas ou soluções criativas para o problema.

Para tanto, foi importante caracterizar o design enquanto área de conhecimento e ferramenta criativa para a personificação do projeto. Adequar à funcionalidade, à expressão, à 
produção de qualquer projeto ao seu público e à indústria. No objeto de design, com uma mensagem atribuída ao produto pode ser definido seu caráter informativo de acordo com sua complexidade funcional e estrutural. Nesta relação há a dependência da originalidade, gerando o que se chama "novidade" fundamental para apresentar estímulo ao consumo.

Um projeto criativo envolve a educação do projetista. O desempenho e o envolvimento do desenhador em sua tarefa é um fator determinante para o ato criativo. Gomes (2004) define desenhador ou projetista como o profissional que participa da construção de características técnico-formal, estético-formais e lógico-informacionais em produtos industriais, ou seja, o Designer. O projeto de Design é constituído por um conjunto de atividades para a criação de produtos industriais relativos a lugares, à ferramentas e a utensílios, com os quais ampliam nossa capacidade sensorial e a elementos de suporte visual que informam e traduzem ações ou ideias. Então, Design é o equacionamento de fatores ergonômicos, estéticos, econômicos e ecológicos no projeto.

O projeto criativo é aquele no qual se utiliza o Design como estruturador e condutor de necessidades físicas e psíquicas necessárias à vida e ao bem-estar de uma sociedade. Agir criativamente é tornar o projeto sinônimo de qualidade de vida e de progresso científicotecnológico.

Por este ponto de vista, o autor eleva o design como atividade projetual e criativa que transforma uma população exigente e qualificada em países em via de desenvolvimento. $\mathrm{Na}$ verdade, o design atinge todos os aspectos relacionados ao ambiente humano condicionado pela produção industrial, fornece os subsídios para o desenvolvimento industrial e fomenta bases informacionais relativas ao produto.

\section{MÉTODO E GESTÃO DO DESIGN}

No âmbito do design, os conceitos de identidade não são absolutos, com parâmetros fixos e fronteiriços. A racionalidade de sua natureza complexa e dinâmica, projeto em Design significa incorporar a interdisciplinaridade como prática na interação com outras áreas que focam qualidade de vida no cumprimento das funções atribuídas na criação.

Westin e Coelho (2011, pg. 24) afirmam que devem ser considerados, em um projeto de Design, a pluralidade, a dinâmica, a incerteza, as inter-relações e a natureza multidimensional. Para os autores o método deve se baseiar em três enquadramentos: 
- Primeiro - considera os objetivos do projeto de um modo mais abrangente, sugere uma nova amplitude para sua compreensão; focaliza o acompanhamento projetual e/ou gestão;

- Segundo - focaliza o processo de realização do projeto, o seu desenvolvimento, que tradicionalmente está associado aos procedimentos metodológicos; utiliza os conceitos de design em novos contextos;

- Terceiro - detém-se sobre os pressupostos da síntese projetual, normalmente associados à inovação ou invenção; representa ações e reflexões a respeito do projeto em contextos mercadológico e acadêmico; sistematiza a prática em exposições teóricas.

Nesta abordagem sobre o método, os autores indicam como sendo o terceiro enquadramento referente ao modo de ensinar em como projetar. As demonstrações empíricas na abordagem do conteúdo teórico devem ser atreladas ao processo sociológico, tecnológico e mercadológico. Estas relações correspondem ao ensino do Design, na dependência do entendimento da diversidade cultural contemporânea e

O processo metodológico engloba uma matriz de construção através de um ordenamento das fases e das ações. Estes conceitos indicam a complexidade de projeto em Design. Uma abordagem metodológica estabelece integração de informações e segurança em aplicá-las no projeto. No modelo metodológico escolhido, por exemplo, pode-se pré-estabelecer e identificar conceitos que guiarão a criação. Projeto em Design conduz a uma lógica positiva:

Se configura como o processo de elaboração do conjunto de documentos necessários à execução de qualquer objeto, seja este de qualquer dimensão ou característica, tendo sido desenvolvido a partir da construção do problema em multiplicadas derivações, por exemplo, quanto a seu significado, quanto a aspectos de produção, quanto a múltiplos aspectos de uso e funcionamento, quanto ao impacto no meio ambiente, quanto às ferramentas projetivas, entre outras tantas, inclusive os aspectos subjetivos de quem projeta. (COELHO, p.268).

Na Educação do Design em disciplinas nas quais o resultado é a inovação e a criatividade é preciso entender que projeto implica o reconhecimento de um processo e de um resultado. Independente do método escolhido para o ensino/aprendizagem o processo de Design deve envolver pesquisa, análise e planejamento estratégico, abordados teoricamente e contextualizados com o uso de ferramentas conceituais e projetivas. 


\section{INSTRUMENTOS DA AVALIAÇÃO}

No Planejamento Pedagógico do curso deverá constar os procedimentos e fundamentações do programa de ensino atrelados às ementas da grade curricular. Cada disciplina irá contemplar um conteúdo programático e um cronograma de atividades. As disciplinas que correspondem à projetação criativa são divididas em aulas práticas e teóricas possibilitando diferentes situações de contextualização nas quais podem ser planejadas em conjunto. Em projetos ou pesquisas em Design, o programa deve contribuir para o despertar das diferentes interfaces estabelecidas para o ensino/aprendizagem, na construção de linguagens assumidas na criação de produtos ou sistemas informativos.

Dentre as formas e conteúdos que colaboram com a evolução do processo de Design, a avaliação é uma das etapas que deverá permitir um olhar periférico e crítico das partes envolvidas. Oliveira (2004) afirma que a avaliação do processo pode ser individual ou coletiva por parte do docente e do discente, bem como a auto-avaliação das respectivas partes para a implementação ou mudanças durante o trabalho. Neste momento avaliativo deverão ser consideradas as reflexões sobre atitudes e métodos utilizados no projeto e no processo de natureza qualitativa e quantitativa. As disciplinas nas quais cabem este processo, estão relacionadas à produção prática de produtos, estruturas ou peças gráficas que passam por um processo avaliativo dos resultados. O conteúdo programático deverá incentivar e contemplar o desenvolvimento e produção relacionados à tecnologia e à criatividade.

Para tanto, é apresentado a seguir um modelo para o planejamento e a condução do processo de educação e de avaliação do ensino/aprendizagem em disciplinas práticas. Nestes itens encontram-se ações e ideias relacionadas aos sistemas de avaliação adotados. As atividades estão divididas nos três processos de avaliação: somativo, diagnóstico e formativo.

\section{Processo somativo}

- Preparação de um conjunto de exercícios práticos manuais, com a manipulação de materiais e exercícios em softwares gráficos no semestre para fixação do conteúdo abordado;

- Os exercícios devem buscar o desempenho do discente durante e após a aula com a apresentação de resultados objetivos. Em aulas práticas deve ser utilizado o laboratório de informática ou ateliês para a produção;

- Disponibilização dos elementos gráficos ou materiais que serão aplicados no projeto;

- Compartilhamento de templates ou modelos com o formato e um briefing das indicações a serem seguidas no trabalho; 
- Estabelecimento de critérios para cada etapa do processo de aprendizagem das técnicas visuais estabelecidas.

\section{Processo diagnóstico}

- Com o resultado dos exercícios trabalhados em laboratório permite condições de detectar falhas, erros e acertos dos discentes para o entendimento do processo de aprendizagem e decisões que o docente pode tomar nas seguintes etapas da disciplina;

- Realização de debates e de discussões para apontamentos da produção prática da turma e fornecendo, a todo momento, condições para que cada discente faça uma reflexão diante de seu desempenho e resultado obtido.

- Algumas discussões devem ser feitas individualmente para sanar quaisquer dúvidas do processo adotado.

\section{Processo formativo}

- Aos exercícios práticos em laboratório, somados a análises de cases e de similares, há condições do aluno desenvolver um trabalho complexo para apresentação final da disciplina;

- Abordagem de questões referentes ao conteúdo teórico aplicado com uma metodologia fragmentada em diferentes momentos para aproximar o discente do processo de trabalho e dos recursos disponíveis para a atividade;

- Na avaliação procurar estabelecer critérios nos quais identifiquem o potencial de cada discente e as habilidades desenvolvidas durante os bimestres;

- Os alunos devem apresentar a proposta em todas as fases do projeto.

Ao final do semestre têm-se resultados otimistas e o uso de parâmetros includentes no ato de atribuição de notas. Levando-se em consideração a evolução do aluno, sua dificuldade e seu desempenho para resolver o problema sugerido.

A sugestão para o trabalho prático parte de um modelo metodológico indicado por Fuentes (2006): Fase Analítica (problemática), Fase Criativa (estudos criativos) e Fase Executiva (modelagem 1D, 2D e 3D).

O tema deverá ser bem definido e híbrido no entendimento do enunciado das questões referentes ao problema e os caminhos sugeridos para uma solução adequada.

Entende-se como a modelagem em uma dimensão (1D) a ideia elaborada na mente ou imaginação transpassada no papel em rafs, croquis ou desenhos bidimensionais representacionais (2D), até mesmo com a utilização de software gráficos. A modelagem em três dimensões pode ser 
entendida como a extrusão das formas, o processo de união de planos bidimensionais com recursos de iluminação, sombra, textura animados ou não.

A fase da modelagem 3D corresponde a materialização similar ao que será realmente construído, nesta etapa é fornecida a base para a construção do produto ou sistema. O produto derivado pode ser chamado de protótipo, modelo, mock-up e maquete nos produtos tangíveis ou layout e boneco para os intangíveis da indústria visual/gráfico/editorial.

\section{Processo avaliativo}

Para o processo avaliativo, sugere-se os seguintes critérios de avaliação a seguir:

- originalidade e adequação ao tema;

- característica compositiva (linguagem visual/conceitual e padrão adotado) - resposta com base na teoria da forma e da cor como meio de expressão bi e tridimensional;

- memorial descritivo, contendo briefing, estudo de campo, ficha técnica e conclusão;

- modelo.

O memorial descritivo deverá conter o briefing com as necessidades estruturais do trabalho e os subproblemas descritos em estudo da linguagem, da função e do conceito com suas principais características.

A consequência da análise de dados e seleção das alternativas é a efetivação de estudos e de layouts criativos. O projeto de Design deverá conter os dados referentes à pesquisa do material que irá ser empregado para a construção do produto ou sistema projetado. No projeto as etapas devem prever tecnologia e recursos adicionais na produção.

Desta maneira sugere-se incluir no enunciado do trabalho itens referentes às fases do material e seu impacto ambiental. As fases desta análise são divididas em pré-produção, produção, distribuição, uso e descarte que compreendem o estudo do ciclo de vida de um material, produto ou sistema. No projeto de design a geração do modelo 3D poderá ser com material similar ao indicado em sua materialização industrial, porém descrito no memorial todos as características e detalhes do processo.

Neste sentido o designer deve utilizar padrões de escala, simulação e semelhança do aspecto original sensorial e ergonômico do projeto para atingir um alto grau de realidade do objeto apresentado como modelo, protótipo ou layout.

Os critérios de avaliação devem corresponder à qualidade textual/visual do trabalho e conceito expresso na criatividade/adequação ao tema proposto. Deve também identificar o diálogo com o Design na apresentação de alternativas ou novas ideias. 


\section{CONCLUSÃO}

Este trabalho procurou esclarecer o processo de Design como caminho para a obtenção de recursos educacionais, estruturais e metodológicos em disciplinas práticas relacionadas com a criatividade. Foram estabelecidos os parâmetros do processo criativo e propostas de um método que ajudam na compreensão do trabalho e no desenvolvimento do projeto.

A tecnologia e as ações educativas voltadas à criatividade e ao ajustamento das fases e etapas do trabalho são ferramentas necessárias para a transmissão do conhecimento e para o bom relacionamento entre as partes envolvidas no processo do ensino/aprendizagem do Design. Os assuntos abordados nos capítulos é fruto de uma constante no atual cenário do universo educativo. Os procedimentos aqui descritos referentes à área da Educação e da arte de projetar ajudam no planejamento e na programação de disciplinas que fomentam a construção de um ser criativo e com referencial cultural.

\section{REFERÊNCIAS}

COELHO, Luiz Antonio L. Conceitos-Chaves em Design. Rio de Janeiro: Novas Idéias, 2011.

COELHO, Luiz Antonio L. Design Método. Rio de Janeiro: Novas Idéias, 2011.

FUENTES, Rodolfo. A Prática do Design Gráfico: uma metodologia criativa. São Paulo: Rosari, 2006.

GOMES, Luiz Vidal Negreiros. Criatividade: projeto, desenho, produto . Santa Maria: sCHDs, 2004.

OLIVEIRA, Eloiza da Silva Gomes de. 0 processo de aprendizagem em uma perpectiva sóciointercionista...Ensinar é necessário, avaliar é possível. Rio de Janeiro: UFRJ, 2004. 